Review Article

\title{
Converting a Microwave Oven into a Plasma Reactor: A Review
}

\author{
Victor J. Law $\mathbb{D}$ and Denis P. Dowling $\mathbb{D}$ \\ School of Mechanical and Materials Engineering, University College Dublin, Belfield D04 V1W8, Dublin 4, Ireland \\ Correspondence should be addressed to Victor J. Law; viclaw66@gmail.com
}

Received 21 February 2018; Accepted 17 April 2018; Published 21 May 2018

Academic Editor: Michael Harris

Copyright ( 2018 Victor J. Law and Denis P. Dowling. This is an open access article distributed under the Creative Commons Attribution License, which permits unrestricted use, distribution, and reproduction in any medium, provided the original work is properly cited.

\begin{abstract}
This paper reviews the use of domestic microwave ovens as plasma reactors for applications ranging from surface cleaning to pyrolysis and chemical synthesis. This review traces the developments from initial reports in the 1980s to today's converted ovens that are used in proof-of-principle manufacture of carbon nanostructures and batch cleaning of ion implant ceramics. Information sources include the US and Korean patent office, peer-reviewed papers, and web references. It is shown that the microwave oven plasma can induce rapid heterogeneous reaction (solid to gas and liquid to gas/solid) plus the much slower plasma-induced solid state reaction (metal oxide to metal nitride). A particular focus of this review is the passive and active nature of wire aerial electrodes, igniters, and thermal/chemical plasma catalyst in the generation of atmospheric plasma. In addition to the development of the microwave oven plasma, a further aspect evaluated is the development of methodologies for calibrating the plasma reactors with respect to microwave leakage, calorimetry, surface temperature, DUV-UV content, and plasma ion densities.
\end{abstract}

\section{Introduction}

Since the 1990s, tabletop domestic microwave ovens have been converted into plasma reactors and used for a wide range of manufacturing applications. The common feature in these reactors is that they contain a multimode resonant cavity (MRC) which is illuminated through one sidewall of the cavity, using a rectangular transverse electric $\left(\mathrm{TE}_{10}\right)$ waveguide with an interior waveguide aspect ratio of $2: 1$ that houses a packaged cavity magnetron operating in the $2.45 \mathrm{GHz}$ range. Using this configuration, no further impedance-matching apparatus is used between the magnetron and MRC.

As these types of microwave oven plasma reactors exploit dielectric heating and plasma chemistry, it is worth noting that dielectric heating of organic materials has a long and established history ranging from medical therapeutic use (short-wave diathermy) in the 1900s [1] and demonstrations of food cooking at the 1933 Chicago World's Fair [2] to the first microwave cooking of foodstuff, with patent application being filed in 1945 [3], followed by the first commercial microwave cooker built and sold by Raytheon in 1947 and Amana in 1967 [2, 4]. These ovens were of limited commercial success due to their bulkiness and cost, but commercial success came later when the cost-effective, packaged cavity magnetron became available $[5,6]$. Although a combination of microwave heating and chemical reactions were reported in the early 1980s, no large-scale oven production was done until rapid synthesis of organic compounds in microwave ovens was performed in 1986 $[7,8]$. More recently (2017), carbothermic reduction of zinc oxide and zinc ferrites has also been reported [9]. Once the first conversion of a microwave oven into a plasma reactor was reported in 1978 [10], plasma-induced synthesis of inorganic compounds became available [11-13], followed by plasma modification of polymer surfaces [14]. Interest in the conversion of microwave oven for plasma processing has also been reported for plasma pyrolysis paper $[15,16]$ and in-liquid plasma decomposition to produce hydrogen gas and carbon films [17-21]. More recently, initial studies of marine diesel exhaust gas abatement within a converted microwave oven have been reported [22]; however, little gasline, or reactor conversion, details were given.

The success of the packaged cavity magnetron and the rectangular $\mathrm{TE}_{10}$ waveguide as found in the standard domestic oven has lead to their reuse in more advanced 
microwave plasma systems that are employed for microwave chemical deposition of diamond-like films [23], in the semiconductor industry [24] and in microwave plasma systems that are designed for the dissociation of hydrogen from water [25]. Plasma reactors based on the microwave oven have also been built for plasma cleaning of contaminated ion implant ceramics [26, 27] and used for plasma removal of photoresistant substances [28]. In 2009, the US Patent US. 2009/0012223 A1 describing a cylindrical cavity driven by a magnetron that generated atmospheric plasma for the fast food industry was also published [29].

Outside the peer-reviewed journals, microwave oven experiments as performed in schools have been reported which range from using plasma balls to explore eggs and the creation of soup sculptures [30]. Semiamateur studies on the subject of microwave oven plasma reactors have also been written. One particular article by Hideaki Page in the Summer/Fall issue of the Bell Jar provides a useful discussion on the practical problems encountered in converting domestic microwave ovens into plasma reactors operating at subatmospheric pressure [31]. Two of the problems encountered are as follows: (1) finding a suitable location for cutting into the thin (typically, 0.75 to $1 \mathrm{~mm}$ ) metal sheet walls of the MRC without causing the metal to bend and buckle and (2) achieving sufficient vacuum in the jam jars or inverted bowls for the plasma to strike. Video postings on https://www.youtube.com/ also provide graphic information on domestic microwave oven plasma cleaning experiments [32]. Most of the other postings indicate that you would not want to do them yourself at home. Indeed, Stanley [33] goes as far as to exemplify many YouTube postings as "wacky and downright dangerous." For completeness, five such postings are given here [34-38].

The aim of this paper is to review the technology of microwave oven plasma reactors, the plasma chemical engineering, and the process measurements used. Within the works reviewed here, plasma processes have been reported quoting different pressure values and pressure units; therefore, to ease comparison between the processes, the original pressure values along with the equivalent SI unit of pressure (Pascal) are presented. This review paper is constructed as follows: Section 2 presents the technology used in microwave oven conversion. Section 3 looks at a purposebuilt microwave plasma reactor that is based on the microwave oven. Section 4 describes the measurements that are used to calibrate the microwave MRC in terms of microwave leakage, calorimetric, surface temperature, nearfield $E$-probe, and plasma ion density measurement. Section 5 provides a look at the cavity magnetron control drive circuit, and finally, Section 6 provides a conclusion to this review.

\section{Microwave Oven Conversions}

2.1. Converted Microwave Oven Plasma Reactors. By way of introduction, it is useful to list the 10 claims in Ribner's 1989 patent [10] that relates to the oven conversion process (Figure 1(a)). In brief, the claims are as follows: (1) positioning a vacuum chamber within the MRC with embodiments for admitting gas into the vacuum chamber and through the cavity and for extracting gas by-products from the vacuum chamber; (2) relating to claim 1 , where a means of regulating the gas to generate uniform plasma in the vacuum chamber; (3) a moving antenna for a means of generating a time average of uniform plasma; (4) a rotating antenna for a means of generating a time average of uniform plasma; (5) a means of reducing microwave leakage around each feedthrough; (6) a means of water cooling substrates within the vacuum chamber during plasma etching without thermal damage to the substrate during the plasma etch process; (7) relating to claim 6 , where the water tubes have a heat transfer relationship with the vacuum chamber with a means of microwave leakage prevention; (8) a means of controlling microwave power; (9) relating to claim 8 , a potentiometer in series with the primary transfer side of the magnetron transformer for controlling the maximum power in the oven; (10) relating to claim 9, when plasma etching of organics from substrate; and finally, (11) relating to claim 10, the use of water cooling of the substrate.

Beyond Ribner's patent, some studies [11-22] show that the microwave oven plasma reactor can be used for a multitude of processes and in many levels of oven reconstruction. The following sections describe the changes required to conventional domestic microwave ovens that range from minimal to major.

2.1.1. The Use of Replaceable Reaction Vessels. An example is the rapid synthesis of phase pure $\mathrm{K}_{3} \mathrm{C}_{60}$ [11] and alkali-metal fullerides [12] in replaceable reaction vessels. Only minor changes to the conventional oven are required such as the provision of providing supports for positioning the reaction vessel at the node or antinode of the microwave field, nor the need for a rotating table or a moving (or rotating) antenna as the objective of the plasma process is to focus the microwave energy onto the sample (Figure 1(b)). In this case, the samples were prepared in an argon-filled Pyrex vessel and then positioned using fire bricks at the node or antinode of the microwave field. The plasma process time is however limited due to the fixed amount of residual gas in the reaction vessel.

2.1.2. The Use of Replaceable Desiccators. Ginn and Steinbock [14] have reported oxygen plasma cleaning of poly(dimethylsiloxane) surfaces within a replaceable desiccator that incorporated a steel electrode to promote plasma ignition (Figure 1(c)). The samples are prepared outside of the microwave oven and then placed in the desiccator which is purged with oxygen for 2 minutes and then evacuated to a pressure of about $10^{-3}$ Torr $(0.133$ Pascal $)$. When placed in the oven and the microwave power $(1100 \mathrm{~W})$ is turned on, the steel wire electrode generates a spark to initiate the oxygen plasma. Here again, the plasma process time is limited, but the use of a steel electrode is found to promote the reaction to end. The subjection of the wire electrode is discussed further in Section 2.1.7.

2.1.3. Pumping through the Wall. In 2010, Singh and Jarvis reported the generation of carbon nanostructures from within 


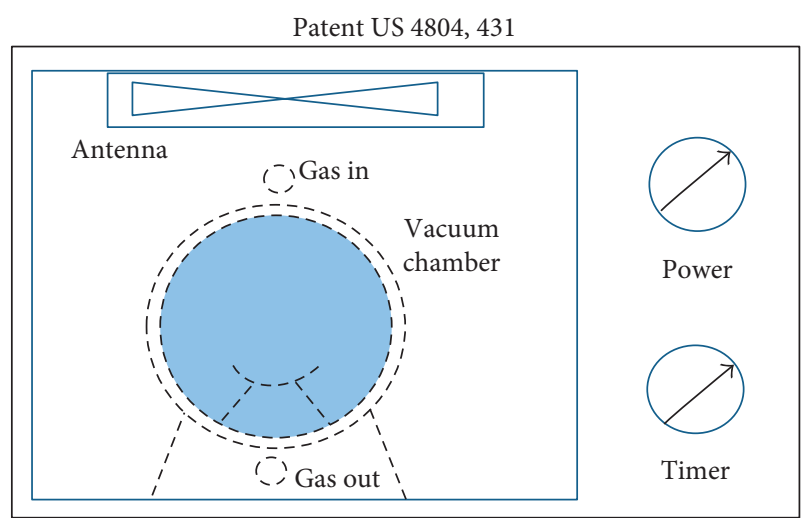

(a)

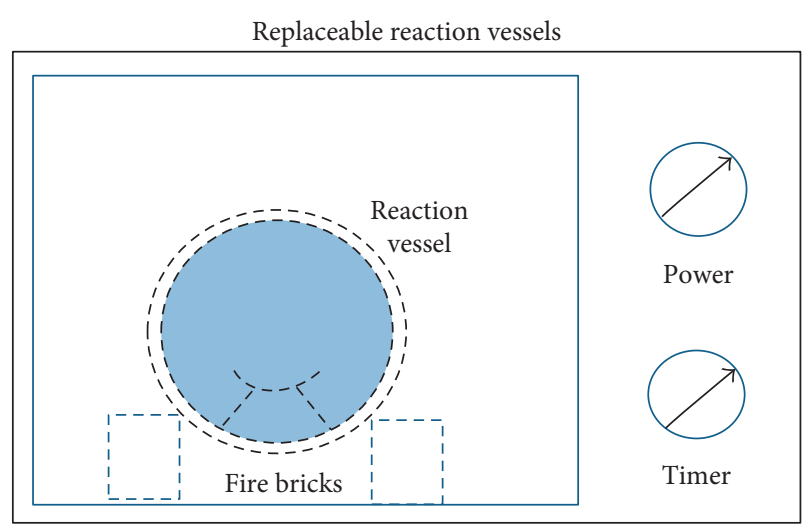

(b)

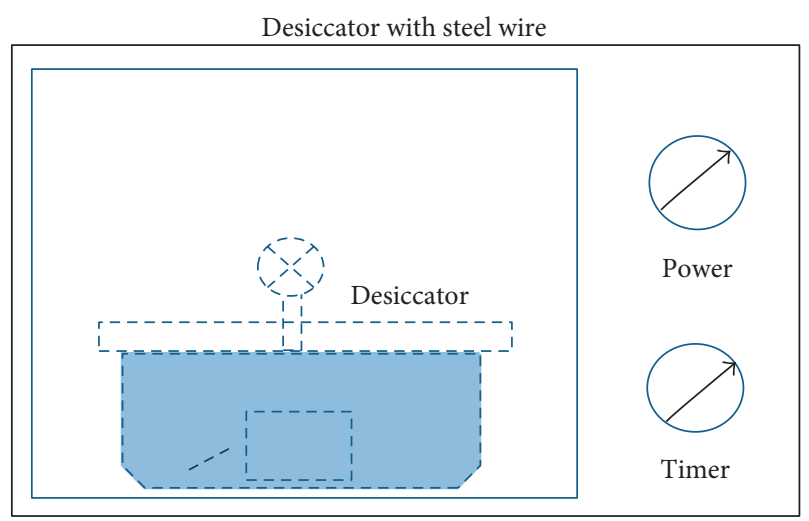

(c) 3-port reaction flask fit to door plus steel aerial electrode

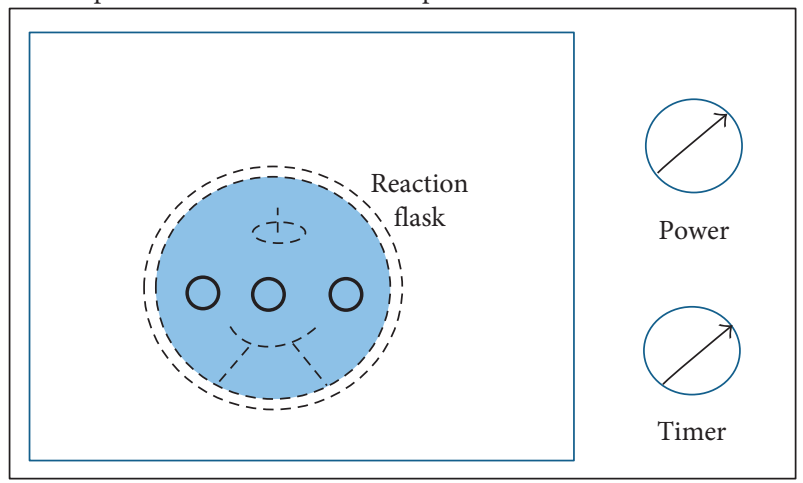

(d)

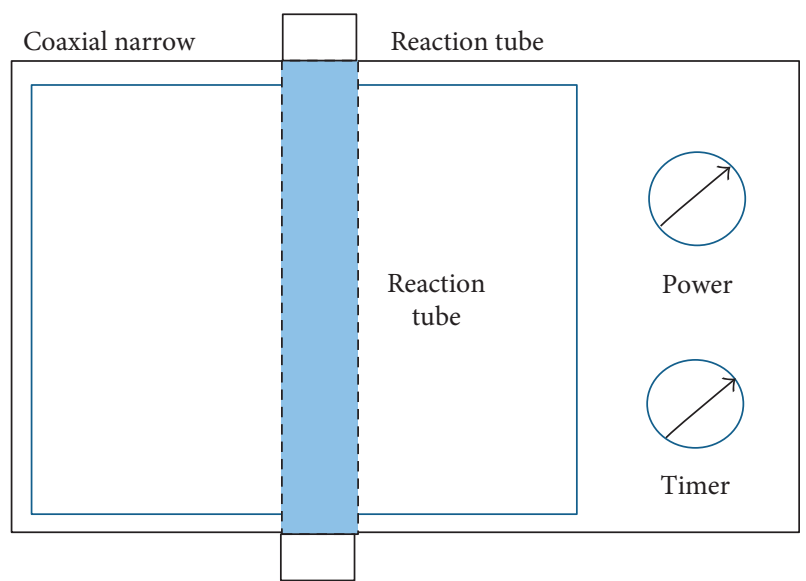

(e)

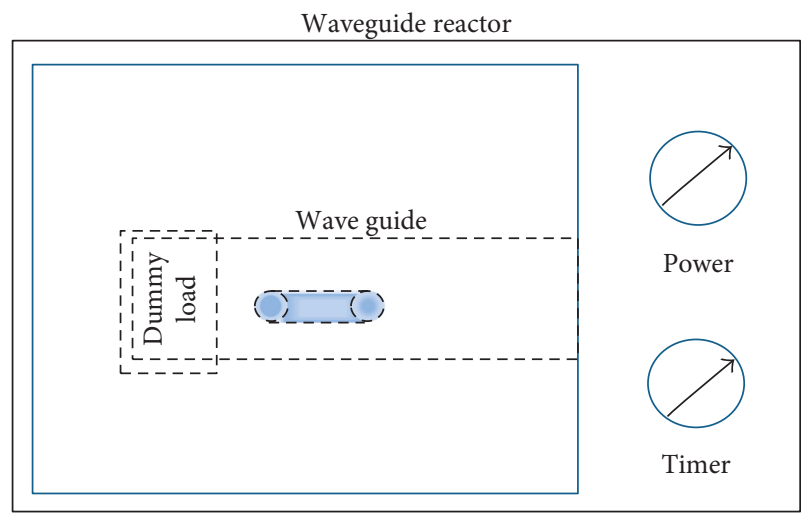

(f)

Figure 1: Front view schematic of converted microwave ovens. Each oven is scaled to the US 4,804,431 patent oven, and for clarity, the auxiliary gas lines and vacuum systems outside the ovens are not shown. (a) Patent US 4,804, 431. (b) Replaceable reaction vessels. (c) Desiccator with a steel wire. (d) Three-port reaction flask fitted to door plus steel aerial electrode. (e) Coaxial narrow reaction tube. (f) Waveguide reactor.

a continuously pumped 3-port reaction flask (made from borosilicate glass and $1000 \mathrm{ml}$ volume) that was held within the microwave oven [17]. To support the vessel and facilitate access to it, the oven door was replaced with an aluminum plate of the same size that has three apertures, one for each flask port. With the flask supported, the flask was evacuated from the outside using one port, while the other two ports are used for the carrier gas and the selected hydrocarbon precursor gases (either ethanol, xylene, or toluene). To enhance the reaction, a $2 \mathrm{~mm}$ diameter aerial electrode made from Nilo $\mathrm{K}^{\circledR}(\mathrm{Ni} 29 \%, \mathrm{Fe} 53 \%$, and Co $17 \%)$ was mounted on a stainless steel base within the reaction flask (Figure 1(d)). As no vacuum pressure or microwave power was reported, it must be assumed that the flask was subatmospheric, and the microwave power was at a maximum $(1000 \mathrm{~W})$. Nevertheless, using this approach, no other modifications to the oven were needed. Two variants of this approach which preserve the door access are found in the work of Page [31] who drilled 
through the bottom of the cavity and Tallaire who drilled through the side of the cavity. In the latter case, Tallaire's YouTube posting provides an example of plasma cleaning of a microscope glass side [32].

2.1.4. Coaxial Narrow Tube Reactor. Khongkrapan et al. have reported a converted microwave oven for pyrolysis of paper to produce gaseous waste by-products at $800 \mathrm{~W}$ $[15,16]$. In their reactor, the process occurs inside a cylindrical quartz tube (internal/external diameters of $27 / 30 \mathrm{~mm}$ and length of $250 \mathrm{~mm}$ ) that coaxially passes vertically through the MRC. Air or argon is used as the precursor gas at a nominal atmospheric pressure $(101.3 \mathrm{k} \cdot \mathrm{Pa})$ with the gas flowing from bottom to top of the MRC. The shredded paper $(5 \mathrm{~g})$ is suspended in the center of the tube (Figure 1(e)). In [16], Khongkrapan et al. state that an igniter was placed within the tube to generate the plasma, but no direct details were given. Upon further reading of their reference list (reference 17 in their paper), a simple cartoon showing the igniter positioned within the tube is given again without text explanation. The subject of igniters in the form of a metal antenna is discussed in Section 2.1.7.

2.1.5. Internal Waveguide. In 2004, Brooks and Douthwaite presented their internal waveguide fitted to an $800 \mathrm{~W}$ domestic microwave oven for plasma-induced processing of powered metal oxides $\left(\mathrm{Ga}_{2} \mathrm{O} 3, \mathrm{TiO}_{2}\right.$, and $\left.\mathrm{V}_{2} \mathrm{O}_{5}\right)$ into binary metal nitrides formed in ammonia $\left(\mathrm{NH}_{3}\right)$ plasma [13]. In this design, a slot is cut at the rear of the MRC to allow a $20 \mathrm{~mm}$ internal diameter U-shaped tube containing the solid-state sample within an alumina boat to be positioned within the microwave field (Figure 1(f)). Outside of the MRC, one end of the U-shaped tube is fitted to a vacuum pump and the other end is fitted to the carrier and process gases. To prevent microwave leakage at the rear of the oven, extensive gasket and Faraday shielding were arranged. An internal waveguide is then fitted to the MRC iris in such a way to focus the microwave energy in the vicinity of the sample. Furthermore, to prevent reflected power damaging the cavity magnetron and overheating the waveguide, a water-cooled dummy load is fitted to the waveguide output aperture. With these extensive oven conversions, the plasma region may be considered to be operating in the coherent mode rather than in the multimode. Typically, plasma parameters used to convert the metal oxides to nitrides are an $\mathrm{NH}_{3}$ gas flow rate of $113 \mathrm{~cm}^{3} \cdot \mathrm{min}^{-1}$, pressure of $20 \mathrm{mbar}$ (2000 Pascal), and microwave power of $900 \mathrm{~W}$ for a plasma exposure time of 2.5 to 6 hours.

2.1.6. Liquid Plasma Vessels. Microwave in-liquid plasma decomposition of $n$-dodecane (molecular formula: $\mathrm{C}_{12} \mathrm{H}_{26}(\mathrm{I})$ ) to simultaneously produce hydrogen gas and carbide in the hydrocarbon liquid has been achieved using a converted microwave oven at a reported microwave power level of 500 to $750 \mathrm{~W}$ [18-20]. A typical representation of these reactors is shown in Figure 2. The reaction is performed in a closed volume Pyrex reaction vessel containing $500 \mathrm{ml}$ of $n$-dodecane

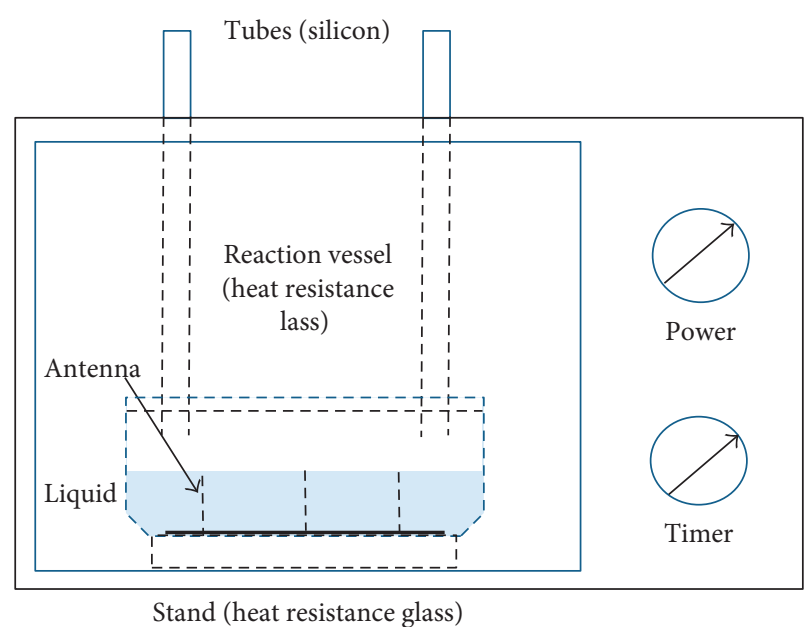

FIgURE 2: A typical front view schematic of a converted microwave oven for liquid processing. For clarity, the auxiliary gas lines outside the ovens are not shown.

liquid with one or more electrodes, where the electrode(s) can be either single-tip steel wire electrodes or copper U-shaped dual-tip aerial electrodes. Also, two silicon/PTFE tubes are inserted from the top of the cavity: one tube is used for sending the carrying gas (argon) as the precursor gas and the second tube is used to collect the spent argon and the by-product gas at a working pressure close to atmospheric pressure.

To understand the purpose of these electrodes, the reaction efficiency of both types of electrodes is examined as a function of the geometry and the number of electrodes in the context of their electromagnetic design and heterogeneous reaction kinetics.

First, consider the single-tip electrodes [18-20]. These metal electrodes have a dimensional length of $L=21 \mathrm{~mm}$ and a diameter of $1.5 \mathrm{~mm}$, and they are fixed vertically in a single array (Figure 3(a)) or in a multiple array (Figure 3(b)) with 1 electrode in the center and up to 6 electrodes circumferentially spaced at a gap separation of $\lambda_{\mathrm{m}} / 4$, where $\lambda_{\mathrm{m}}$ is the wavelength of the microwave radiation passing through the medium. The wavelength calculation is given in the following equation:

$$
\lambda_{\mathrm{m}} \sim \frac{C}{f} \cdot \frac{1}{\sqrt{\varepsilon_{\mathrm{r}}}} .
$$

The approximate expression in (1) is used as the operation frequency of the free running cavity magnetron is frequency pulled by changing SWR conditions in the rectangular $\mathrm{TE}_{10}$ waveguide in which the magnetron is mounted. All other symbols have their normal meaning: $C$ is the speed of light $\left(2.99792 \times 10^{8} \mathrm{~m} \cdot \mathrm{s}^{-1}\right), f$ is the magnetron operating frequency $(2.45 \mathrm{GHz})$, and $\varepsilon_{\mathrm{r}}$ is the medium in which the radiation is passing through. Thus, for the liquid $n$-dodecane ( $\varepsilon_{\mathrm{r}}=1.78$ to 2$), \lambda_{\mathrm{m}}$ approximates to $8.85 \mathrm{~cm}$ and $\lambda_{\mathrm{m}} / 4$ approximates to $2.2 \mathrm{~cm}$.

Based on the works [18-20] and the work of Pongsopon et al. [21], it is generally considered that the electrodes have three well-defined roles: to confine the plasma to the immediate proximity of the electrode(s) tip, to function as 


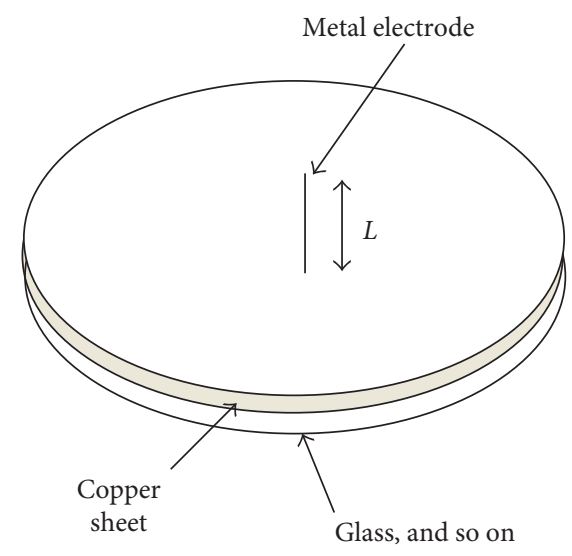

(a)

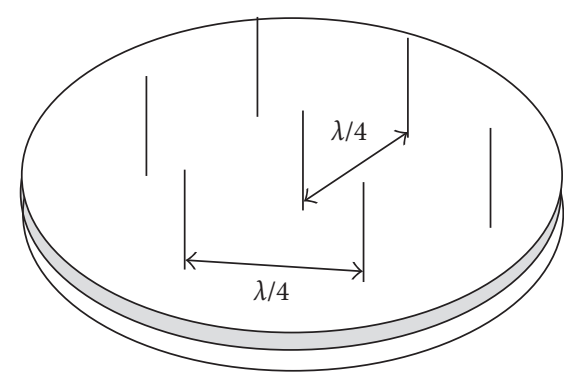

(b)

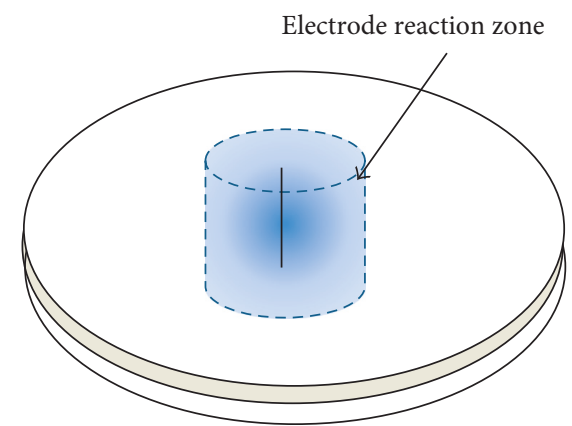

(c)

Figure 3: Typical single-tip electrode arrangement (a); multiple electrode arrangements (b); electrode reaction zone (c).

a catalytic source for plasma heterogeneous reaction, and in the case of manufacturing carbon nanomaterials, to provide a substrate on which the carbon material can grow. In the first of these roles, increasing the number of electrodes from 1 to 6 has revealed that the efficiency of plasma decomposition of $n$-dodecane does increase, but beyond 6-7 electrodes, the reaction efficiency becomes rate-limited. This may be due to electromagnetic power loss by the resonant structure of the electrodes [20] or simply that the addition of more than 7 electrodes and their associated surrounding reaction zones (cylindrical volume around each electrode; Figure 3(c)) within a fixed closed volume simply produces a loading effect within the heterogeneous reaction [39]. That is to say, as the percentage of the combined electrode reaction zones approaches the total fixed volume, the amount of fresh reactant flowing to the electrode reaction zone becomes reduced. Therefore, mass transport in and out of each electrode reaction zone, rather than plasma decomposition, may become the rate-limiting step. To clarify these observations, further investigation is needed.

For the dual-tipped aerial electrode, Toyota et al. [20] have shown that the $\mathrm{U}$-shaped aerial electrodes have distinct optimum lengths of $L \sim 2 \lambda_{\mathrm{m}}, 3 \lambda_{\mathrm{m}} / 2, \lambda_{\mathrm{m}}$, and $\lambda_{\mathrm{m}} / 2$. They also show that the use of the approximation sign in (1) is justified by experimentally determining the $\lambda / 2$ FHHW length of the U-shaped dual-tip aerial electrode to be 4.4 to $4.7 \mathrm{~cm}$ for n-dodecane.

2.1.7. Igniter. The description of construction and use of wire aerial electrodes for plasma ignition is now used as an aid to outline the construction of the plasma igniter [16] and the drawing in [40] (Figure 4). Assuming that the drawing in [40] may be scaled, the plasma igniter may be constructed in two ways: Firstly, the igniter may be constructed using two wire electrodes opposing each other and bent at $45^{\circ}$ so that their tips are aligned with the gas flow, and the fixing location is formed using an insulating ring. The second and more practical arrangement is that the igniter is preformed from a $30 \mathrm{~mm}$ diameter $\times 0.5 \mathrm{~mm}$ thick steel steel disc, and a plurality of electrodes are punched from the central portion of the disc and bent to a $45^{\circ}$ angle. For the purpose of this second option, the construction of a 4-electrode igniter is exemplified using the $27 / 30 \mathrm{~mm}$ internal/external diameter glass tube in [16] as a reference tube (Figure 1(e)). A schematic of the manufacturing stages of the igniter is given in Figure 4, where it is shown that the first stage is to punch out the form of the igniter, the second stage is to bend the electrodes, and the third stage is to align the igniter to the glass tube. Using this method of construction, the lip of the preform can self-align to enable the 4 aerial electrodes to suit the plasma ignition criteria as described in Section 2.1.5.

2.1.8. Production of Plasmoids (Fireballs). The production of plasmoids, sometimes called fireballs or ball-lightning, within domestic microwave ovens has been posted on YouTube postings [34-38]. Perhaps, the simplest way of producing a fireball without modification to the microwave oven is to place a partially sliced grape (that has its two halves connected via a thin piece of skin) in the microwave oven and then turn on the microwave power for 3-10 seconds. The YouTube posting [34] shows that arc-like plasmoids are generated at the thin skin bridge that connects the two grape halves, with the discharge emission continuing until either the power is turned off or the grapes have shriveled up. This action may be understood by considering that the two freshly cut grape halves have a characteristic dimension of 1.5 to $2 \mathrm{~cm}$ and are partially filled with a conducting electrolyte, the combination of which creates an organic conducting dipole antenna not unlike the metal antennas discussed in Sections 2.1.5 and 2.1.6. Given this understanding, it is reasonable to assume that as the free electrons are pushed back and forth through the narrow thin skin bridge of the grape, heat is generated due to the 


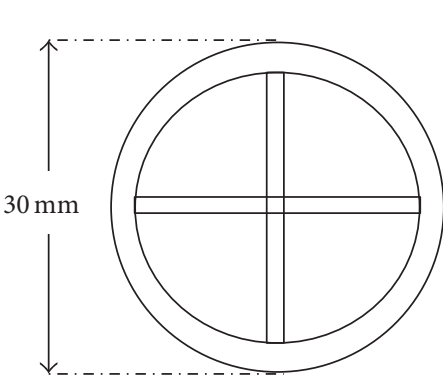

(1) Punch stage

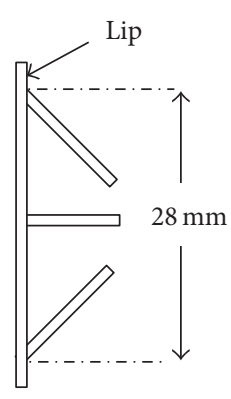

(2) Bend stage

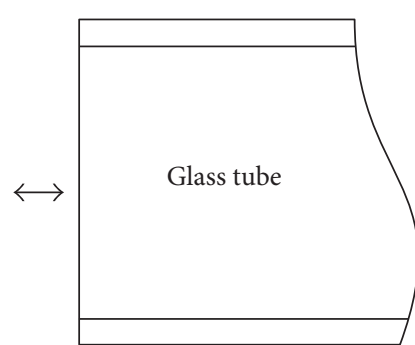

(3) Glass tube fitting

FIGURE 4: Manufacturing stages of the disc igniter that is suitable for a narrow glass tube reactor.

resistance and burns away the skin. In addition, the movement of electrons through the grape electrolyte induces a rapid increase in temperature, causing vaporization of the electrolyte to a cloud of electrons and ions, thus forming the localized plasmoid. The plasmoid continues to be sustained as long as the free electrons are available from the diminishing volume of the grape electrolyte.

Moving away from the organic source for generating plasmoids, a lighted safety match, supported by a wine cork, covered with a glass jar, and placed within the center of the MRC, can also be used [35]. Upon turning on the microwave power, a plasma discharge is generated that rises to the top of the jar, thus forming a buoyant plasmoid. Warren [36] used a similar approach, but this time using a glass jar supported by three wine corks and a lighted cigarette placed in the gap provided by the corks. In this work and the previous example, the plasmoids are maintained when the thermal source is extingusihed. It is only when the microwave power is turned-off does the plasmoid become extinguished. Plasmoids can also be generated within electric light bulbs and fluorescence tubes as shown in [37]: this example also appears to be the basis for the near-field E-probe (Section 4.4).

A more dangerous approach to generating plasmoids is demonstrated in [38] where a cavity magnetron connected to a food tin can is used to lunch microwaves at a domestic light bulb to produce a plasmoid within the bulb. From this experiment, it would appear that the electric filament acts as the initiating electrode.

Before finishing this section, it is worth noting that the cylindrical plasma reactor produced for the fast food industry [29] employed a patented passive plasma catalyst in the form of an electrode to ignite the atmospheric plasma [41], where the passive plasma catalyst can include any object capable of inducing plasma by deforming the local electric field. On the other hand, the patent states that an active plasma catalyst produces particles or a high-energy wave packet capable of transferring a sufficient amount of energy to a gaseous atom (or molecule) to remove at least one electron from the gaseous atom (or molecule) in the presence of electromagnetic radiation. Given these two definitions, it is reasonable to assume that the safety match flame [35], cigarette [36] and grape [34] can be classed as an active plasma catalyst and the metal electrode as a passive plasma catalyst.
2.1.9. Plasmoid Food Cooking. The Korean patents [42, 43] and conference paper [44] report on a form of tuning within the $\mathrm{TE}_{10}$ waveguide that fall outside the scope of this review, but they are listed for three reasons: Firstly, the phenomena of plasmoids extend the cooking range of the domestic microwave oven from one of dielectric heating of food stuff to one that provides surface browning and imparting texture and flavor that is similar to the traditional flame-cooking process. Secondly, Jerby et al. [44] have noted that plasmoids produced in this way require wire antenna electrode to ignite the plasmoid and therefore may contain nanoparticles, which might be harmful for the food quality and even make it inedible. Thirdly, the additional use of plasma discharge that generates ozone and ions for the removal of odorproducing materials from the cooking chamber [45] does provide one possible technical route forward in the future development of the domestic microwave oven.

\section{Purpose-Built Microwave Oven Plasma Reactor}

This section describes the methodology used in the construction of a purpose-built microwave oven plasma reactor. Of particular importance in this regard is the MRC series of plasma reactors that were built in the mid-1990s at Cambridge Fluid Systems Ltd (England, UK). The design concept behind these plasma reactors was to build a simple reliable and cost-effective table-top plasma reactor that could be sold to research laboratories and low-volume productions units. Their main use was for surface engineering enhancement in the microelectronic, semiconductor sector and the manufacture of bodyshell of Formula One racing cars.

The design of the plasma reactor is similar to microwave ovens, where the cavity magnetron antenna is located within a $\mathrm{TE}_{10}$ waveguide that is used to illuminate the MRC through a single iris. The cutoff frequency $\left(f_{c}\right)_{m, n}$ of the $\mathrm{TE}_{10}$ waveguide is calculated using the following equation:

$$
\left(f_{\mathrm{c}}\right)_{m, n}=\frac{C}{2} \sqrt{\left(\frac{m}{a}\right)^{2}+\left(\frac{n}{b}\right)^{2}},
$$

where $c$ is the speed of the light and $a$ and $b$ are the internal dimensions (width and height) of the waveguide; in this case, 80 and $38 \mathrm{~mm}$ are used, respectively, which equate a cutoff frequency of $1.875 \mathrm{GHz}$. 
With the cavity magnetron antenna positioned $26 \mathrm{~mm}$ from the end of the waveguide, the frequency and bandwidth of the magnetron are allowed to be free running. Thus, the noncoherent reflected power passing through the iris travels back to the magnetron thus altering the SWR of the coherent wave within the $\mathrm{TE}_{10}$ waveguide, resulting in varying the output power of the magnetron.

The MRC reactor design differs from the domestic microwave oven plasma reactor in the following ways (also cf. Figure 1 with Figure 5):

(i) The chassis, MRC, and waveguide are constructed as one welded component using $1.4 \mathrm{~mm}$ thick mild steel sheet. Before each of the three components is welded together, they have all the necessary holes punched and clasp nuts fixed. Once welded, the structure is nickel plated to produce a metal structure that is robust with sufficient stiffness to support all the additional components (the front and rear stainless flanges, gas lines, DC power supply pressure gauge, etc.). Using this construction approach, the MRC has a theoretical maximum unloaded $Q$-factor $\left(Q_{u}\right)$ in the TE mode that is dependent on the ratio of stored energy in the cavity $\left(V_{c}\right)$ to the energy loss to the cavity walls $\left(\delta \times A_{\mathrm{c}}\right)$ :

$$
Q_{\mathrm{u}}=\frac{2 V_{\mathrm{c}}}{\delta A_{\mathrm{c}}},
$$

where $\delta$ is the electrical skin depth at the cavity wall per cycle and $A_{c}$ is the cavity wall area.

For this reactor, the main cavity has an approximately $Q_{\mathrm{u}}$ of 20,000 at a resonant frequency of $2.45 \mathrm{GHz}$.

(ii) A cylindrical Pyrex glass chamber $(190 \mathrm{~mm}$ diameter, $300 \mathrm{~mm}$ length, and $5 \mathrm{~mm}$ wall thickness: producing a volume of 3 liters) is located within the multimode cavity with its longitudinal axis perpendicular to the microwave iris and with the front and rear of the chamber housed within metal flanges that form the part of the multimode cavity wall. The rear flange contains welded vacuum and pressure gauge ports, and the front flanges contain the access door. This design maximizes the chamber volume and removes all fragile glass fittings, plastic tube connectors, and feedthrough microwave leakage gaskets.

(iii) The gas lines are fitted within the chassis and to the side of the MRC, thereby enabling the process gasses to be injected through multiple equally spaced radial ports in the front flange thus reducing the possibility of precursor gas being preionized prior to chamber entry and maximizing uniform gas flow and plasma uniformity along process chamber longitudinal axis.

3.1. Plasma Cleaning of Ion Implant Ceramic Insulators. Ion implantation is one of the key processes in the high volume (220 wafers per hour) manufacture of silicon

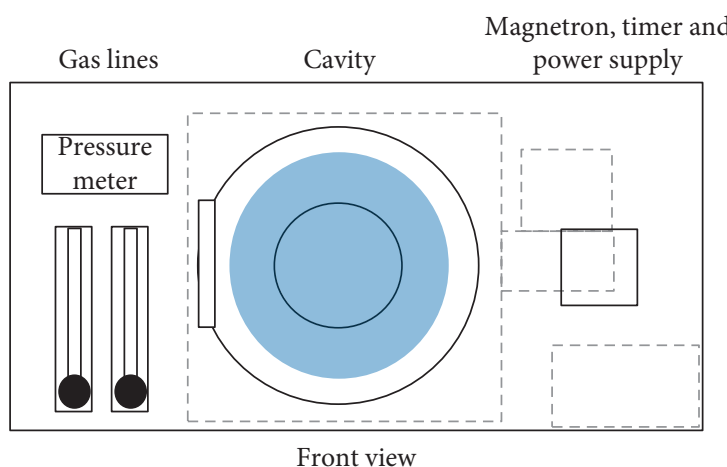

(a)

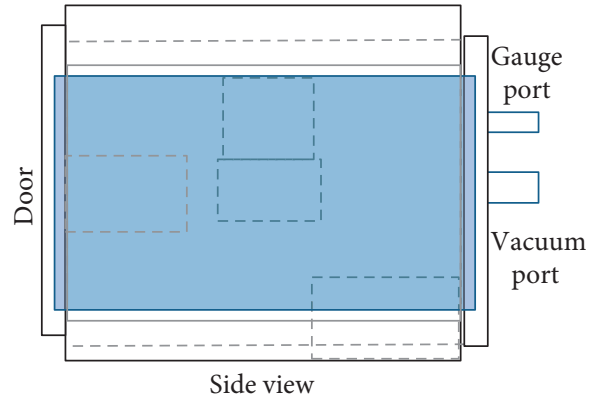

(b)

FIGURE 5: Typical front and side view schematic of the MRC plasma reactor chassis and cavity. Photograph of the microwave MRC-200 plasma reactor.

semiconductor devices. These ion implant machines, however, cost between $\$ 1.8 \mathrm{M}$ and $\$ 3 \mathrm{M}$. These machines are also highly maintenance-intensive systems with high capital cost; therefore, availability and cost of ownership are major factors to be considered. Many of the parts changed during regular maintenance, and ion source changes are ceramic insulators. In this section, an overview of the plasma cleaning of ion implant ceramic is described: for full details of the process, see $[26,27]$. The plasma cleaning process has been performed in the MRC series of plasma reactor using a gas mixture of $5-10 \% \mathrm{O}_{2}$ in CF, with an admixture of $50 \%$ by flow of argon. The argon admix is used to stabilize the microwave plasma by moderating the electron energy distribution and to provide a uniform excited species throughout the plasma volume. The plasma etch chemistry at the surface of the ceramic may be considered to proceed by the following representative heterogeneous reaction:

$$
3 \mathrm{CF}_{4}(\mathrm{~g})+1.5 \mathrm{O}_{2}(\mathrm{~g})+2 \mathrm{X}(\mathrm{s}) \rightarrow 2 \mathrm{XF}_{3}(\mathrm{~g})+3 \mathrm{COF}_{3}(\mathrm{~g}),
$$

in which the addition of $\mathrm{O}_{2}$ scavenges carbon from the $\mathrm{CF}_{4}$ through the formation of $\mathrm{COF}_{x}$ species to enhance the steady-state concentration of $\mathrm{F}$ atoms in the plasma volume. The element $\mathrm{X}$ in reaction (4) represents the group $\mathrm{V}$ element (As, $\mathrm{P}$, and $\mathrm{Sb}$ ) on the ceramic surface, and the $\mathrm{XF}_{3}$ are the etch products. Given sufficient microwave power, the etch rates of these products are therefore controlled by the 
production of $\mathrm{F}$ atoms $\left(\mathrm{O}_{2}\right.$ balance $)$, product volatility, and ceramic microscopic surface area.

For the MRC-100 reactor, typical plasma process parameters obtained were $104 \mathrm{~W}$ and $10 \mathrm{mbar}$ with an etch time of 45 minutes, where the surface temperature of the ceramics reached $80 \pm 5 \mathrm{~K}$. In the case of the MRC- 200 reactor, the process parameters were as follows: $200 \mathrm{~W}$ and 10 mbar (1000 Pascal) with an etch time of 20 to 25 minutes, where the surface temperature of the ceramics reached $125 \pm 5 \mathrm{~K}$.

\section{Microwave Cavity Calibration}

This section describes a range of different techniques which are used for the evaluation of the microwave efficiency as well as leakage.

4.1. Microwave Leakage Measurement. The European Directive 2004/40/EC and ICNIRP (1998) guidelines recommend that industrial microwave ovens have surface microwave $(3-300 \mathrm{GHz})$ radiation power density levels $>5 \mathrm{~mW} \cdot \mathrm{cm}^{-2}$ and 5 times less for domestic microwave ovens intended for general use. Applying a quadratic law based on plane wave theory, an operator standing at a distance of $20 \mathrm{~cm}$ from an industrial oven, the operator will receive the maximum allowable power density level of $3 \mathrm{~mW} \cdot \mathrm{cm}^{-2}$. For domestic oven environment, this equates to a power density level of $0.3 \mathrm{~mW} \cdot \mathrm{cm}^{-2}$. In the context of converted ovens intended for plasma, many feedthrough and apertures in the $\mathrm{MRC}$ require considerable care in design and construction to prevent microwave leakage.

4.2. Calorimetric Magnetron Power Calibration. The magnetron power entering the MRC may be calibrated using the water open-dish load method, see, for example, British Standard 7509:1995 and IEC 1307:1994. Hence, given the heat capacity of water is $4.184 \mathrm{~J} /(\mathrm{g} \cdot \mathrm{K})$, the calculated applied power $(P)$ within the cavity may be obtained by placing a known mass of water $(m)$ within the cavity and heating it for a short period of time $(t)$, making sure the water does not boil. With the knowledge of the measured water temperature change $(\Delta T=$ final temperature - initial temperature), the microwave power entering into the cavity is calibrated for a given power setting using the following equation (see also [40]):

$$
P=\frac{m C \Delta T}{t}
$$

The calibration however must be considered to be an upper value for plasma processing as its dielectric volume will be different from the water calibration. (Note: when the process chamber volume or the geometric shape does not allow the open dish method to be used, the alternative flow method can be used, as outlined in [46]).

Given (4), the microwave power density $\left(\mathrm{W} \cdot \mathrm{cm}^{-3}\right)$ of a system may be calculated by dividing through by the process chamber volume. The following open-dish load method for the MRC 100 is given here as an illustrative example: the MRC-100 and MRC-200 reactors have a calculated magnetron applied power of $104 \mathrm{~W}$, which equates to a power density of $0.116 \mathrm{~W} \cdot \mathrm{cm}^{-3}$. For the MRC-200 reactor, the calorimetric measurements produce magnetron applied power values of $200 \mathrm{~W}\left(0.022 \mathrm{~W} \cdot \mathrm{cm}^{-3}\right)$ and $450 \mathrm{~W}$ $\left(0.05 \mathrm{~W} \cdot \mathrm{cm}^{-3}\right)$.

4.3. Surface Temperature Measurement. Knowledge of the surface temperature of materials immersed in the plasma is useful in understanding the heterogeneous plasma-surface interaction. This is of particular importance when local dielectric heating has the potential of thermal runaway, because most materials increase their dielectric loss with temperature [12]. Two simple means of estimating local surface temperature of materials that are immersed in microwave plasma have been used. For surface temperatures below $180 \mathrm{~K}$, liquid crystal temperature-sensitive $(20 \pm 5 \mathrm{~K}$ to $180 \pm 5 \mathrm{~K})$ strips attached to the plasma immersed surface can be used [27]. For higher temperatures, salts of known melting point $(\mathrm{KCl}=1043 \mathrm{~K}$ and $\mathrm{NaCl}=1074 \mathrm{~K})$ sealed in silica capillaries have been used [13].

4.4. Near-Field Plasma E-Probe Measurement. Attempts to strike a plasma outside the ignition pressure limits of 0.1 to 20 mbar (10 to 2000 Pascal) result in the microwave radiation being stored "per cycle" in the empty-cavity mode; under these conditions, the rate of energy loss to the cavity wall can substantially heat the MRC structure, and in the extreme case, the microwave radiation leakage can become a health risk. Additionally, if the MRC is loaded with materials (semiconductor wafers and low dielectric strength material), these can be electrically or mechanically damaged. It therefore becomes necessary to have an automatic power cutoff device to prevent microwave leakage and damage to both the reactor and loaded materials. The near-field plasma E-probe as described by Law [47] is one such device that helps monitor such events. In this circuit, a neon discharge lamp, a photodiode, and a reference voltage are connected as shown in Figure 6, with one leg of the neon being used protruding into the cavity to act as a near-field $E$-probe. In the original circuit design, a strip chart is used to record the voltage-time-series data, but with today's analogue-todigital converters and software (such as LabView) the plasma ignition state-space and plasma state-space may be monitored with trigger levels set to give a binary $\mathrm{Go} / \mathrm{No}$ control output [24, 47].

4.5. Bébésonde Electrostatic Probe Measurement. For plasma processes, it is generally considered that the ion flux arriving and leaving the surface determines the plasma process. However, the use of electrostatic probe techniques to determine the ion density and temperature of plasma driven by modulated power source in the presence of sputtered insulating material is problematic. Such is the case of plasma containing $\mathrm{CF}_{4}$. This section describes a probe technique that is tolerant of drive modulation and sputtered insulating materials. The following measurements were performed at 


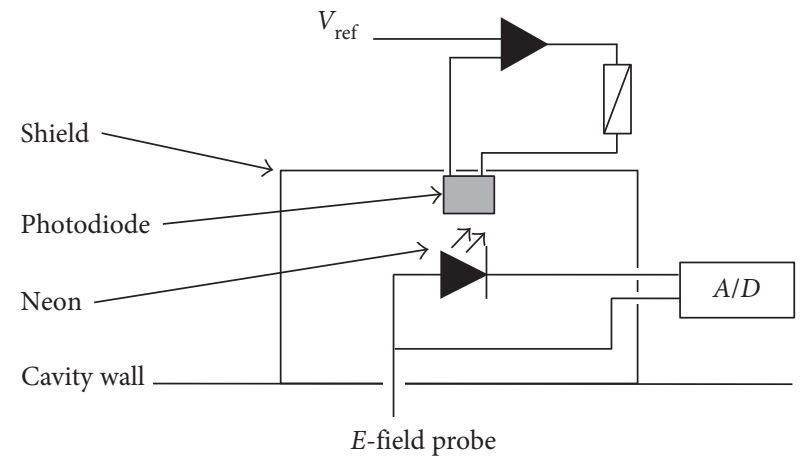

FIGURE 6: Schematic of the E-probe circuit, showing a neon discharge lamp, a photodiode, and an analogue-to-digital converter.

the Oxford Research Unit, Open University, on the MRC100 reactor. The probe used is an RF-biased ion flux probe (known colloquially as "Bébésone, or BBs"). For full details of the probe and measurement, see [48].

For good probe measurements, visual observations of the plasma volume as a whole and around the probe itself are usually required. For the MRC reactors, it was found necessary to replace the standard front flange door with a flange incorporating a probe port and inspection port, covered by an open mesh. Given this modification, argon plasma within the MRC-100 visually exhibits little structure with a slight brightening close to the dielectric annulus boundary. Nevertheless, there is no evidence of microwave structure in the optical emission, which indicates that energy is rapidly homogenized in the electron population.

Following these visual baseline inspections, the Bébésonde was used to determine the ion flux in the low power and high setting with argon gas flow varying from a maximum $\left(51 \cdot \mathrm{min}^{-1}\right)$ to a minimum for which plasma could be sustained $\left(2 \mathrm{l} \cdot \mathrm{min}^{-1}\right)$. For the MRC-200 reactor, argon ion densities are measured to be in the range of $2 \times 10^{11} \cdot \mathrm{cm}^{-3}$ at $50 \mathrm{mbar}(5 \mathrm{k} \cdot \mathrm{Pascal})$ to $3 \times 10^{12} \cdot \mathrm{cm}^{-3}$ at 1 mbar (100 Pascal), and the electron temperature is in the range of 1 to $1.5 \mathrm{eV}$ for an input power of $0.022 \mathrm{~W} \cdot \mathrm{cm}^{-3}$ : the higher plasma density at low pressure corresponds to a longer mean free path and increased electron power transfer.

4.6. Ultraviolet Fluorescence Microwave Probe. For many processing plasmas, photon energy $(E=h c / \lambda)$ varies from $10 \mathrm{eV}$ to $1 \mathrm{eV}$ with preferential intensity at discrete spectral wavelengths. The spectral characteristic is determined by the nature of gas excitation and relaxation processes, both of which are sensitive to the local electron temperature and gas excitation cross sections. Gas composition and mode of plasma production therefore has a major impact on UV production and plasma chemistry.

The ultraviolet fluorescence probe utilizes activated rareearth salts: $\mathrm{Y}_{2} \mathrm{SiO}_{5}$ :Ce (absorption $<200 \mathrm{~nm}$ ) and $\mathrm{Zn}_{2} \mathrm{SiO}_{4}$ : $\mathrm{Mn}$ and $\mathrm{Y}_{2} \mathrm{O}_{3}: \mathrm{Eu}^{3+}$ (absorption $<300 \mathrm{~nm}$ ). For full details of these probes, see [49]. At these energies, the host lattice $(\mathrm{H})$ undergoes electronic excitation via the production of electron-hole pair separation (6), followed by the lowest energetic deactivation pathway fluorescence at wavelengths longer than the initial radiation. In general, the fluorescence spectrum is composed of a narrow band with the precise wavelength determined by the intimate relation between the activator ( $\mathrm{Ce}, \mathrm{Mn}$, and $\mathrm{Eu}^{3+}$ ) and the host lattice and by the irradiating photon radiation:

$$
\begin{aligned}
& H: A+h v^{\prime} \rightarrow H: A^{*} \quad\left(h v^{\prime}>4 e v\right), \\
& H: A^{*} \rightarrow H: A+h v^{\prime \prime} \quad\left(h v^{\prime \prime}<4 e v\right) .
\end{aligned}
$$

The most simple form of the probes comprises a synthetic DUV grade fused silica capsule $(12 \mathrm{~mm}$ diameter $\times 20 \mathrm{~mm}$ ) containing one of three activated salts at a nominal reduced pressure of $10 \mathrm{mbar}$. The fused silica has transmittance $T=0.5$ at $170 \mathrm{~nm}$. When placed in the plasma volume, the probe collects $4 \pi$ steradians of incoming DUV photon radiation. The emitted fluorescence is viewed through an optical crown glass viewport $(T=0.5$ at $380 \mathrm{~nm})$. Due to the dielectric capsule, photoluminescence rather than electroluminescence is considered to be the prime mechanism of fluorescence in these probes. The dielectric also acts as a wavelength discriminator and provides the upper working limit of the probe to be $1100 \mathrm{~K}$

Using these knowledge, the salts $\mathrm{Zn}_{2} \mathrm{SiO}_{4}: \mathrm{Mn}$ and $\mathrm{Y}_{2} \mathrm{O}_{3}$ : $\mathrm{Eu}^{3+}$ (placed in their own capsule) integrates DUV plasma, while $\mathrm{Y}_{2} \mathrm{SiO}_{5}$ :Ce when placed directly in the plasma volume integrates VUV $(<200 \mathrm{~nm})$ plasma, thus their fluorescence appearing in the green, red, and blue, respectively.

\section{Magnetron Oven Control Circuits}

Microwave ovens generally employed one of two types of magnetron drive circuits. For microwave ovens with lowpower outputs (typically $<500 \mathrm{~W}$ ), the output power is achieved by pulse-width modulation of a single incident power to the magnetron with the cooking time set between 0 and 30 minutes. Between the $500 \mathrm{~W}$ and $1100 \mathrm{~W}$ rating, continuous application of the microwave power is used where the power level is set by the magnetron drive capacitor value:

$$
P=\frac{1}{2}\left(C V^{2}\right) f .
$$

The choice of either of these two drive circuits can have an impact on the magnetron control circuit ability to carry out the selected plasma process. This choice is exemplified by comparing the short and low power requirements of rapid plasma syntheses of organic compounds $[7,8]$, cleaning of glass slides and polymers [14] to that of the high power and long processing times of solid-state metal oxides processing [13] and the plasma cleaning of ion implant ceramic insulators $[26,27]$.

5.1. Cavity Magnetron Capacitor-Controlled Drive Circuit. In this section, the choice of the capacitor controlled drive circuit is considered along with its safety control circuit that is used in the MRC-100/200 plasma reactors. A schematic of 


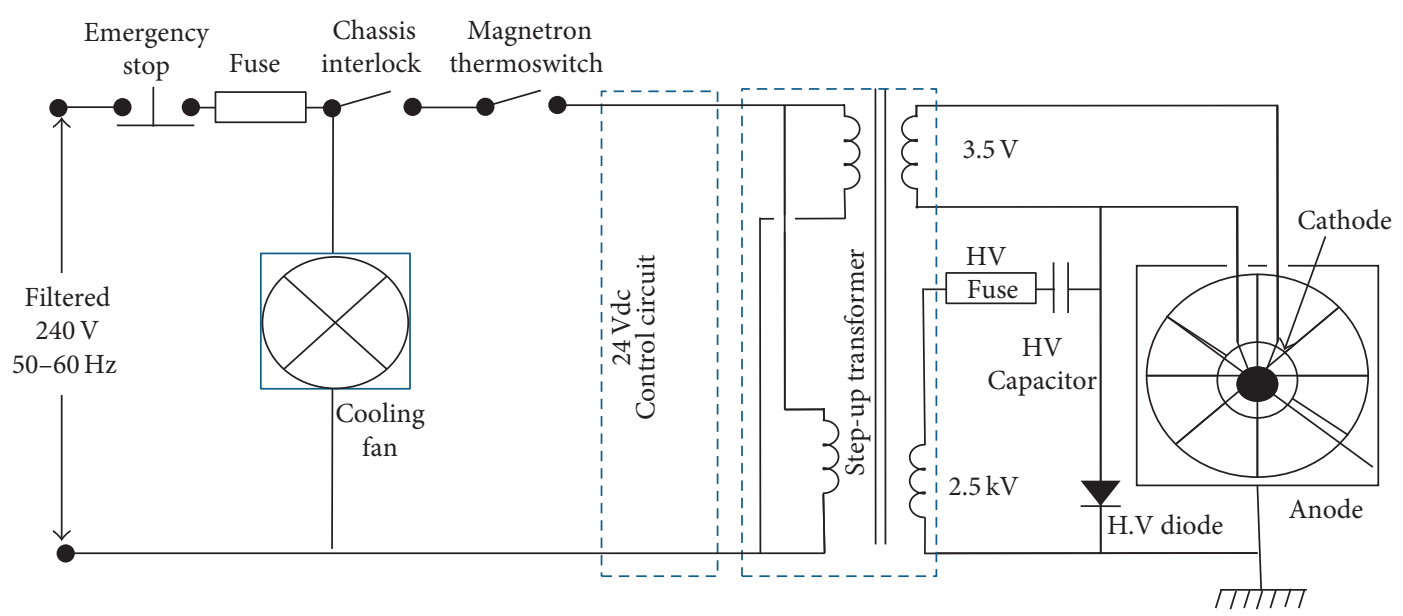

FIGURE 7: Cavity magnetron capacitor-controlled dive circuit. The $24 \mathrm{~V}$ DC control circuit represented by the dashed box is discussed in Section 5.2.

the capacitor controlled drive circuit is shown in Figure 7. A similar cavity magnetron capacitor controlled drive circuit is reported in [23]. Chaichumporn et al. have also reported further refinement of the magnetron anode voltage (3.3 to $6.6 \mathrm{kV})$ in [40].

The transformer comprises two winding circuits: The first provides a winding ratio to produce $240 \mathrm{~V}$ at $50-60 \mathrm{~Hz}$ to approximately $3.5 \mathrm{~V}$ at $50-60 \mathrm{~Hz}$ for the cathode heater, and the second provides the step-up voltage $(240 \mathrm{~V}$ at $50-60 \mathrm{~Hz}$ to $2-3 \mathrm{kV}$ at $50-60 \mathrm{~Hz}$ ). The HV capacitor $(0.6$ to $1.5 \mu \mathrm{F}$ ) and the HV diode are used to bias the cathode negative with respect to the anode block, which contains the magnetron's cavity structure. Using this arrangement, the capacitor value and diode determines the DC power dissipated in the magnetron cavity structure. For safety reasons, both passive and active control components are incorporated on either side of the setup transformer. These include the following: the circuit is fused on both sides of the transformer plus an emergency stop button, a chassis interlock, a magnetron thermoswitch $\left(135^{\circ} \mathrm{C}\right)$, and a chasse cooling fan. In addition, $24 \mathrm{~V} \mathrm{DC}$ circuit is used to provide remote passive and active control of the drive circuit (see Section 5.2).

5.2. 24 V DC Control Circuit. In purpose-built microwave oven plasma reactors, the auxiliary equipment (vacuum pumps, vacuum valves pressure gauge, gas lines, purge lines, process timer, and microwave power) is synchronized to plasma process in a safe manner. The role of the $24 \mathrm{~V}$ DC control circuit is to synchronize the auxiliary components to the plasma process and shut down the system in the case of an emergency failure: this is especially important when using flammable, corrosive, and toxic precursor gases and by-products. The circuit is designed so that all chasse controls are isolated from the cavity magnetron capacitor-controlled drive circuit using relays and solenoids. It should be noted that when converting a domestic microwave oven into a plasma reactor, the synchronization has to be built from scratch.

\section{Conclusions}

This work has reviewed the conversation of the domestic microwave oven into a source for cleaning as well as chemical reactions. The conversion of domestic systems into plasma reactor is described, as is the construction of purpose-built microwave oven plasma reactors. Calibration of the MRC has been discussed along with identifying the two types of magnetron drive circuitry used. The professional and armature use has also been presented, in the latter case, mainly limited to kitchen top experiments. The proof of principle and small batch processes established in these plasma reactors range from plasma cleaning of glass and polymer surface and removal of toxic metals from ceramic surfaces to the manufacture of carbon nanostructures and the pyrolysis of paper to produce gaseous waste by-products. In all cases, the power source is the package cavity magnetron operating below $1100 \mathrm{~W}$ output power and pressures ranging from a few $0.1 \mathrm{~s}$ Pascal to a nominal atmospheric pressure (101.3 Pascal).

At or close to atmospheric pressure single or multiple wire antenna electrodes that have a physical length approximating to $1 / 4$ or $1 / 2$ of the microwave length in which that it is immersed have been found to play a catalytic role in instigating plasma production, and in the case of manufacturing carbon nanomaterials provide a substrate on which carbon material can grow. With regard to reaction rate, increasing with the number ( 1 to 6 ) of electrodes beyond which the reaction becomes rate-limited, a geometrical loading effect around the wire antenna is proposed in this paper. Whether this or electromagnetic power loss is responsible for the effect, further work is required. In addition, this work has reconstructed a preformed disc aerial electrode (igniter) suitable for a narrow tube reactor $[16,40]$ (Figure 4).

The safety match flame, lighted cigarette, sliced grape, and metal antenna electrode have been observed to have a catalyst role in the production of plasma and plasmoids. To distinguish between the metal antenna and the thermalchemical based catalyst, it has been put forward that metal 
antennas may be classified as a passive catalyst as they only supply a surface that generates free electrons, whilst the safety match flame, lighted cigarette, and sliced grape may be classified as an active catalyst as they supply energy in the form of heat and free electrons from an electrolyte.

Finally, this review also has highlighted plasmoid food cooking within a MRC and the use of plasma discharge for removing food odor from microwave ovens. Given that food safety issues are addressed, it is reasonable to envisage microwave oven plasma reactors, incorporating both plasmoid cooking of food stuff and plasma deodorization of cooking by-products may be realized in the near future.

\section{Conflicts of Interest}

The authors declare that there are no conflicts of interest regarding the publication of this paper.

\section{Acknowledgments}

The authors would like to acknowledge the support of SFI through the I-Form Advanced Manufacturing Research Center 16/RC/3872.

\section{References}

[1] F. Nagelschmidt, Diathermy Text Book for Physicians and Students, Springer-Verlag, Berlin, Heidelberg, 1921.

[2] Davis, A History of the Microwave Oven, The IEEE News Source, The IEEE News Source, Piscataway, NJ, USA, https:// www.theinstitute.ieee.org/tech-history/technology-history/ahistory-of-the-microwave-oven.

[3] P. L. Spencer, "Method of treating foodstuffs," US Patent 2,495,429, 1950.

[4] J. M. Osepchuk, "The history of the microwave oven: a critical review," in Proceedings of Digest IEEE International Microwave Symposium, pp. 1397-1400, Boston, MA, USA, June 2009.

[5] J. R. Mims, “Microwave magnetron," US Patent 3,739,225, 1973.

[6] T. Koinuma, "Magnetron," US Patent 3,809,590, 1974.

[7] R. N. Gedye, F. Smith, and K. C. Westaway, "The rapid synthesis of organic compounds in microwave ovens," $\mathrm{Ca}$ nadian Journal of Chemistry, vol. 6, no. 1, pp. 17-26, 1988.

[8] R. N. Gedye, W. Rank, and K. C. Westaway, "The rapid synthesis of organic compounds in microwave ovens. II," Canadian Journal of Chemistry, vol. 69, no. 4, pp. 706-711, 1991.

[9] M. Omran, T. Fabritius, E.-P. Heikkinen, and G. Chen, "Dielectric properties and carbothermic reduction of zinc oxide and zinc ferrite by microwave heating," Royal Society Open Science, vol. 4, no. 9, p. 170710, 2017.

[10] A. Ribner, "Microwave plasma etching machine and method of etching," US Patent 4,804,431, 1989.

[11] R. E. Douthwaite, M. L. H. Green, and M. J. Rosseinsky, "Rapid synthesis of phase pure $\mathrm{K}_{3} \mathrm{C}_{60}$ using a microwaveinduced argon plasma," Journal of the Chemical Society, Chemical Communications, no. 18, pp. 2027-2028, 1994.

[12] R. E. Douthwaite, M. L. H. Green, and M. J. Rosseinsky, "Rapid synthesis of alkali-metal fullerides using a microwaveinduced argon plasma," Chemistry of Materials, vol. 8, no. 2, pp. 394-400, 1996.
[13] D. J. Brooks and R. E. Douthwaite, "Microwave-induced plasma reactor based on a domestic microwave oven for bulk solid state chemistry," Review of Scientific Instruments, vol. 75, no. 12, pp. 5277-5279, 2004.

[14] B. T. Ginn and O. Steinbock, "Polymer surface modification using microwave-oven-generated plasma," Langmuir, vol. 19, no. 19, pp. 8117-8118, 2003.

[15] P. Khongkrapan, N. Tippayawong, and T. Kiatsiriroat, "Thermochemical conversion of waste papers to fuel gas in a microwave plasma reactor," Journal of Clean Energy Technologies, vol. 1, no. 2, pp. 80-83, 2013.

[16] P. Khongkrapan, P. Thanompongchart, N. Tippayawong, and T. Kiatsiriroat, "Fuel gas and char from pyrolysis of waste paper in a microwave plasma reactor," IJEE, vol. 4, no. 6 , pp. 969-974, 2013.

[17] R. Singh and A. L. L. Jarvis, "Microwave plasma-enhanced chemical vapour deposition growth of carbon nanostructures," South African Journal of Science, vol. 106, no. 5-6, p. 4, 2010.

[18] S. Nomura, H. Toyota, S. Mukasa, H. Yamashita, T. Maehara, and A. Kawashima, "Production of hydrogen in a conventional microwave oven," Journal of Applied Physics, vol. 106, no. 7, p. 073306, 2009.

[19] S. Nomura, H. Yamashita, H. Toyota, S. Mukasa, and Y. Okamura, "Simultaneous production of hydrogen and carbon nanotubes in a conventional microwave oven," in Proceedings of International Symposium on Plasma Chemistry (ISPC19), vol. 65, Bochum, Germany, July 2009.

[20] H. Toyota, S. Nomura, and S. Mukasa, "A practical electrode for microwave plasma processes," International Journal of Materials Science and Applications, vol. 2, no. 3, pp. 83-88, 2013.

[21] R. Pongsopon, T. Chim-Oye, and M. Fuangfoong, "Microwave plasma reactor based on microwave oven," in PIERS Proceedings, pp. 2723-2726, Guangzhou, China, August 2014.

[22] N. Manivannan, W. Balachandran, R. Beleca, and M. Abbod, "Microwave plasma system design and modelling for marine diesel exhaust gas abatement of NOx and SOx," International Journal of Environmental Science and Development, vol. 6, no. 2, pp. 151-154, 2015.

[23] M. C. Savadori, V. P. Mammana, O. G. Martins, and F. T. Degasperi, "Plasma-assisted chemical vapour deposition in a tunable microwave cavity," Plasma Sources Science and Technology, vol. 4, no. 3, pp. 489-494, 1995.

[24] V. J. Law and N. Macgearailt, "Visualization of a dual frequency plasma etch process," Measurement Science and Technology, vol. 18, no. 3, pp. 645-649, 2007.

[25] Y. H. Jung, S. O. Jang, and H. J. You, "Hydrogen generation from the dissociation of water using microwave plasmas," Chinese Physics Letters, vol. 30, no. 6, p. 065204, 2013.

[26] V. J. Law and D. Tait, "Contaminated ceramic plasma cleaning," European Semiconductor, vol. 19, no. 9, pp. S38S41, 1997.

[27] V. J. Law and D. Tait, "Microwave plasma cleaning of ion implant ceramic insulators," Vacuum, vol. 49, no. 4, pp. 273-278, 1998.

[28] T. M. Burke, E. H. Linfield, D. A. Ritchie, M. Peper, and J. H. Burroughs, "Hydrogen radical surface cleaning of GaAs for MBE regrowth," Journal of Crystal Growth, vol. 175-176, pp. 416-421, 1997.

[29] D. Tasch, D. J. Brosky, S. Conrad, S. Kumar, and D. Kumar, "Microwave plasma cooking," US Patent 2009/0012223 A1, 2009.

[30] H. Stanley, "Microwave experiments at school," Science in School, vol. 12, pp. 31-33, 2009. 
[31] H. Page, "Microwave oven plasma reactor," Summer/Fall, vol. 10, no. 3-4, pp. 11-13, 2001.

[32] A. Tallaire, "Plasma cleaning in modified microwave oven at LSPM (CNRS)," https://www.youtube.com/channel/ UCfG3h7mSltjtsKcXH0dFCHQ.

[33] H. Stanley, "Plasma balls: creating the 4th state of matter with microwaves," Science in School, vol. 12, pp. 24-29, 2009.

[34] Soxfreak5243, "Grapes making fireballs in the microwave," https://www.youtube.com/watch?v=JrD6yzemDRw.

[35] Stupideaproductions, "Microwave plasma: awesome experiment," https://www.youtube.com/watch?v=G7lfzA7WzVI.

[36] J. P. Warren, "Microwave plasma experiment," https://www. youtube.com/watch? $\mathrm{v}=\mathrm{CNMjCggFKzM}$.

[37] W. Sajado, "10 destructive science experiments with microwave. Be really careful when using microwave!, https://www. youtube.com/watch?v=8Yv9o8aFTuk.

[38] Kreosan, "What microwave oven is capable. Generated plasma," https://www.youtube.com/watch?v=RrOw03gIIQQ.

[39] V. J. Law, G. A. C. Jones, N. Patel, and M. Tewordt, "Loading effects in $\mathrm{CH}_{4}$ and $\mathrm{H}_{2}$ Morie of GaAs," Microelectronic Engineering, vol. 11, no. 1-4, pp. 611-614, 1990.

[40] C. Chaichumporn, P. Ngamsirijit, N. Brkoonklin, K. Eaiprasetsak, and M. Fuangfoong, "Design and construction of $2.45 \mathrm{GHz}$ microwave plasma source at atmospheric pressure," Procedia Engineering, vol. 8, pp. 94-100, 2011.

[41] D. Kumar and S. Kumar, "Plasma assisted joining," US Patent 7,309,843 B2, 2007.

[42] K. Y. Gyeong and R. J. Gwan, "Heating device of microwave oven," KR Patent 20010004084, 2001.

[43] S. C. Bo, L. Y. Woo, and S. S. Wom, "Heater apparatus for microwave oven," KR Patent 100766440, 2007.

[44] E. Jerby, Y. Meir, R. Jaffe, and I. Jerby, "Food cooking by microwave-excited plasmoid in air atmosphere," in Proceedings of 14th International Conference on Microwave and High Frequency Heating, pp. 17-30, Nottingham, UK, 2013.

[45] W. H. Lee and H. J. Kim, "Cooking device with deodorization," US Patent 2009/0110592 A1, 2009.

[46] N. F. Alekseev, D. D. Malairov, and I. B. Bensen, "Generation of high-power oscillations with a magnetron in the centimeter band," Proceedings of the IRE, vol. 32, no. 3, pp. 136-139, 1944.

[47] V. J. Law, "Microwave near-field plasma probe," Vacuum, vol. 51, no. 3, pp. 463-468, 1998.

[48] N. J. Brathwaite, J. P. Booth, and G Gunge, "A novel electrostatic probe method for ion flux measurements," Plasma Sources Science and Technology, vol. 5, no. 4, pp. 677-684, 1996.

[49] V. J. Law, "Ultraviolet fluorescence microwave plasma probe," Vacuum, vol. 49, no. 3, pp. 217-220, 1998. 


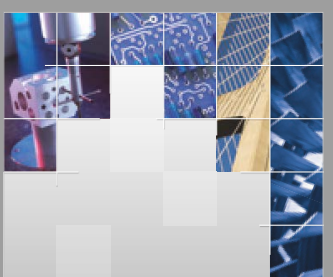

\section{Enfincering}
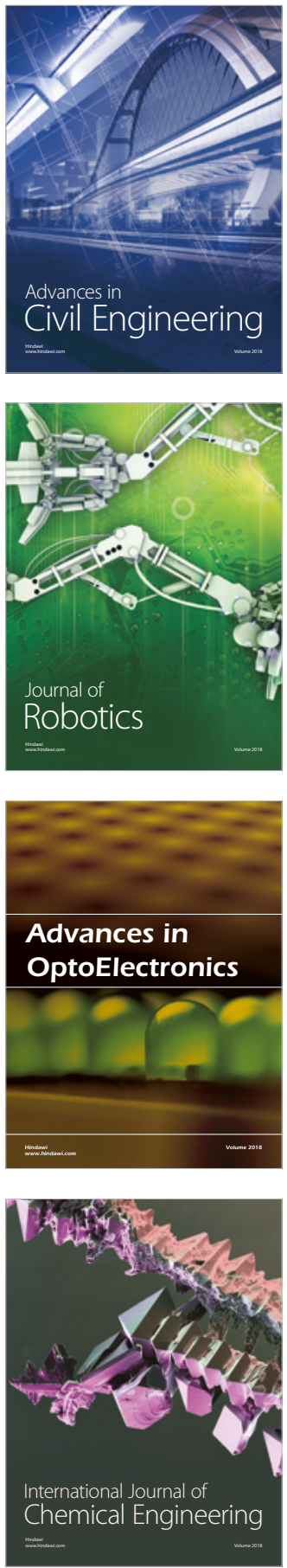

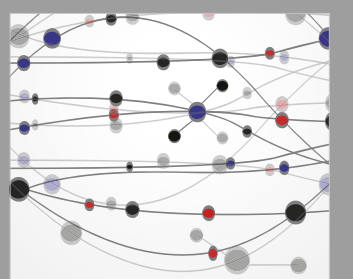

\section{Rotating \\ Machinery}

The Scientific World Journal

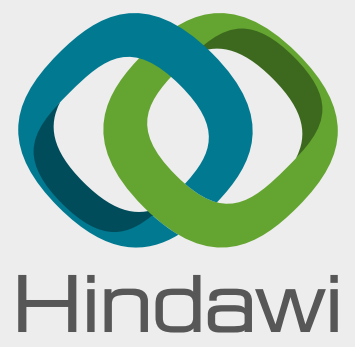

Submit your manuscripts at

www.hindawi.com
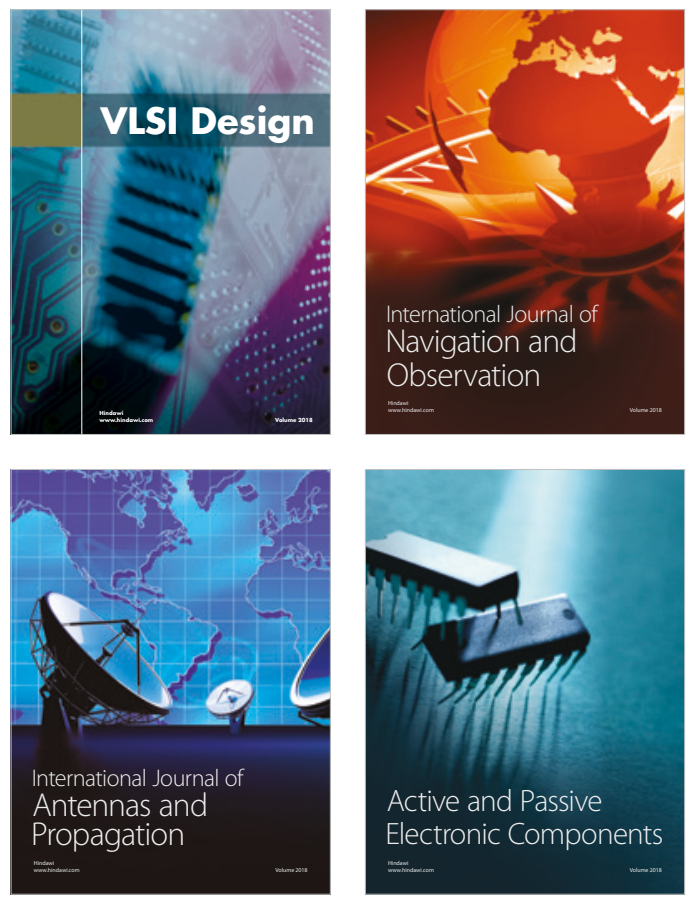
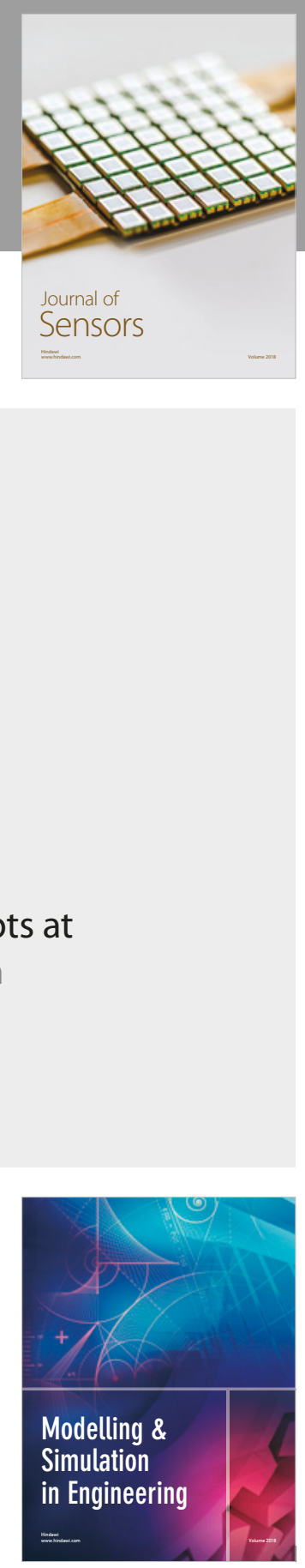

\section{Advances \\ Multimedia}
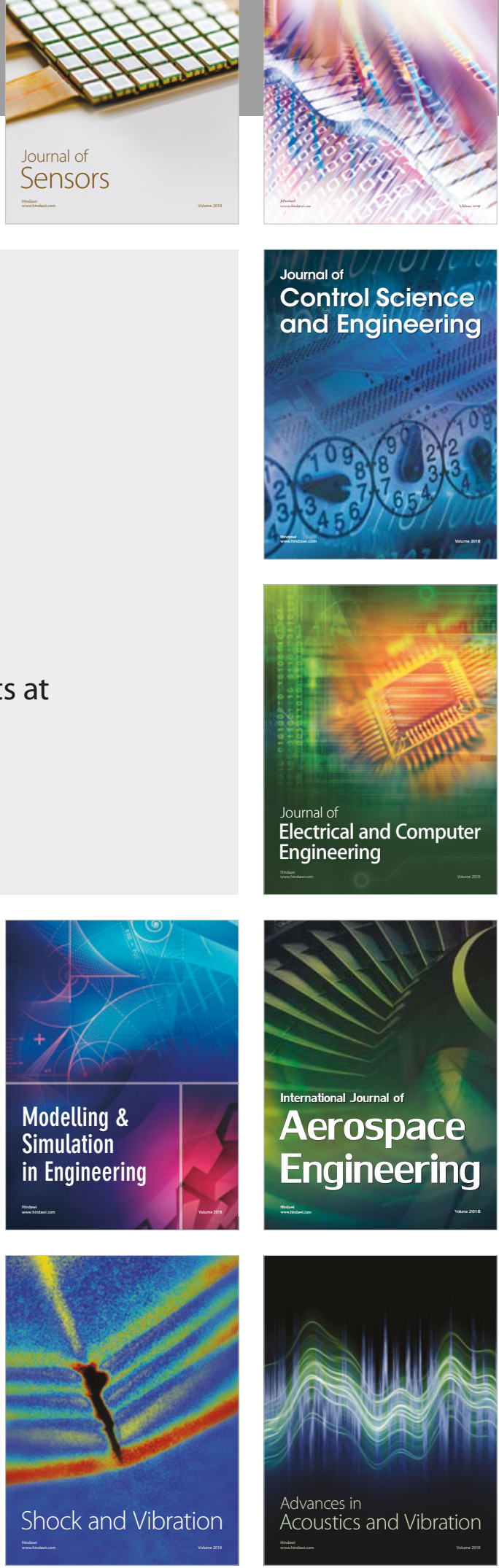